\title{
Proliferaciones linforreticulares del pulmón
}

\author{
JOSÉ SALINAS A.*, ISABEL LEIVA R.* y SERGIO GONZÁLEZ B.*
}

\section{Pulmonary lymphoproliferative lesions}

The present review describes the current classification of the pulmonary lymphoproliferative lesions as proposed by the WHO in 2004 with emphasis in the clinical picture and histopathological features. The definition of these entities includes the clinical picture, histopathology, immunohistochemistry and molecular features. The differential diagnosis of the most important entities is also briefly discussed.

Key words: Lymphoma, MALT, lymphomatoid ganulomatosis, lung.

\section{Resumen}

En el presente trabajo de revisión se describe la clasificación actual de las lesiones linfoproliferativas del pulmón propuesta por la OMS el año 2004 con énfasis en el cuadro clínico y los aspectos histopatológicos. La definición de estas entidades incluye cuadro clínico, histopatología, inmunohistoquímica y características moleculares. Se discute brevemente el diagnóstico diferencial de las formas más importantes.

Palabras clave: Linfoma, MALT, granulomatosis linfomatoide, pulmón.

\section{Introducción}

Las lesiones linforreticulares del pulmón son poco fecuentes y dentro de éstas, los linfomas primarios son aún más raros y se estima corresponden al $1 \%$ de todos los linfomas y al $0,5 \%$ de todos los tumores pulmonares. La mayoría son linfomas no-Hodgkin de células B y de bajo grado similares a los de otras localizaciones extranodales. La enfermedad de Hodgkin pulmonar primaria es muy rara, siendo solamente el $1 \%$ de todos los casos de enfermedad de Hodgkin. La mayoría de los casos corresponde a una invasión pulmonar por extensión directa desde el mediastino o por recurrencia hematógena.

La evidencia actual sugiere que la mayoría de los linfomas primarios del pulmón se origina del tejido linfático asociado al bronquio (BALT, bronchial associated lymphoid tissue), similar al tejido MALT (mucosal associated lymphoid tissue) del sistema gastrointestinal. Como otros linfomas MALT, se cree que el linfoma BALT se origina a partir de una hiperplasia linfoide por selección neoplásica de un clon anormal, después de una estimulación antigénica repetida o sostenida.

La nomenclatura ha sido confusa en las últimas décadas ya que tanto las hiperplasias como las neoplasias del BALT han recibido variadas denominaciones, tales como linfoma pulmonar primario BALT, "BALToma", pseudolinfoma, etc. La clasificación de los linfomas nodales se ha aplicado por extensión a las lesiones pulmonares causando aún mayor confusión, debido a la complejidad de la terminología. Por ello es que la clasificación actual vigente, propuesta por la OMS en 2004, reconoce cuatro condiciones que podrían considerarse neoplasias linforreticulares primarias del pulmón (Tabla 1). A éstas habría que agregar la enfermedad de Hodgkin y la hiperplasia linforreticular (ex-pseudolinfoma). El término pseudolinfoma se considera vago y más bien obsoleto y no se recomienda su uso como categoría diagnóstica, ya que los estudios actuales han demostrado que muchas de las lesio-

* Departamento Enfermedades Respiratorias y Anatomía Patológica. Escuela de Medicina, Pontifica Universidad Católica de Chile. Santiago, Chile. 
nes convencionalmente definidas como pseudolinfomas son en realidad linfomas primarios de bajo grado; del mismo modo la denominación Neumonía intersticial linfocitaria o LIP se debe limitar a lesiones inflamatorias.

A continuación, se describen las formas más frecuentes de las proliferaciones linforreticulares del pulmón con énfasis en los aspectos clínicos, patológicos y moleculares.

\section{Linfoma de zona marginal $B$ o tipo MALT, bajo grado}

Definición. Puede definirse como un linfoma extranodal constituido por linfocitos B pequeños con células monocitoides, linfocitos, inmunoblastos y centroblastos dispersos con diferenciación plasmocítica (Figura 1). El infiltrado linfocitario está en la zona marginal de folículos reactivos y alcanzan regiones interfoliculares, y además característicamente se extiende al epitelio bronquiolar formando las llamadas lesiones linfoepiteliales (Figura 2). Del 70 a 90\% de las proliferaciones linfocíticas en el pulmón corresponden a un linfoma de bajo grado.

Cuadro clínico. Afecta a hombres y mujeres de mediana o avanzada edad en similar proporción. La mitad de los casos es asintomática y el tumor suele descubrirse accidentalmente en una radiografia de tórax de rutina. Otros pacientes pueden quejarse de disnea, tos, hemoptisis y dolor torácico. Baja de peso y fiebre puede estar presentes en una minoría de los casos. Radiológicamente, el $70 \%$ de los casos muestran nódulos solitarios o infiltrados y más de un quinto son bilaterales. El tamaño de las lesiones es variable, de pocos centímetros hasta opacar un pulmón

Tabla 1. Clasificación OMS de tumores linfoproliferativos primarios del pulmón, 2004

Linfoma de zona marginal B o tipo MALT Linfoma de células grandes $\mathrm{B}$, difuso

Granulomatosis linfomatoide

Histiocitosis de células de Langerhans

Tabla 2. Grados histológicos de la Granulomatosis linfomatoide (Lipford et al, 1988, Blood)

Grado 1: sin necrosis; polimorfismo+; menos de $5 \%$ $\mathrm{EBV}+$

Grado 2: necrosis focal; polimorfismo+; 5-20\% EBV+

Grado 3: necrosis extensa; monomorfismo+; grupos $\mathrm{EBV}+$

EBV: ADN del virus de Epstein-Barr entero. Se ha descrito derrame pleural en $28 \%$ de los casos. La cavitación del tumor es extremadamente rara. La radiografía de tórax rara vez muestra adenopatías metastásicas o regionales. Aproximadamente $30 \%$ se presentan con gamopatía monoclonal.

Por definición, la mayoría de los linfomas de bajo grado en el pulmón se localizan en el pulmón al momento de presentación con poca tendencia a generalizarse. Puede extenderse a linfonodos periféricos y médula ósea en un cuarto de los pacientes que recaen. Casi la mitad de los casos reaparecen usualmente antes de los tres años, pero en ocasiones hasta después de una década. Las recaídas en el pulmón, pleura y mediastino son comunes, no así las extratorácicas. Al contrario, el linfoma gastrointestinal u otro linfoma MALT extranodal pueden extenderse al pulmón, algunas veces después de muchos años.

La naturaleza indolente se demuestra en pacientes que son diagnosticados después de 5 años de observación radiológica sin mayores cambios, alta sobrevida y ausencia de diseminación. Las opciones de tratamiento varían según las circunstancias individuales, debido a que no existe un protocolo unificado para el linfoma pulmonar. Los tratamientos más usados son sólo resección, resección más quimioterapia y sólo quimioterapia. No se ha observado diferencias significativas en las tasas de sobrevida (84 a 94\% a 5 años). Los pacientes sin síntomas sistémicos tienen mejor sobrevida. La transformación de linfoma de bajo grado del BALT en linfoma de células B grandes de alto grado se ha observado en recaídas y generalmente agrava el curso clínico de la enfermedad.

Histopatología. Histológicamente, las características diagnósticas se aprecian mejor en una biopsia abierta o por videotoracoscopia. Lo más importante para el diagnóstico es que la mayoría de las características histológicas consideradas antiguamente como típicas de hiperplasia linfoide, se consideran hoy en día como propias de linfoma marginal.

El linfoma de bajo grado pulmonar frecuentemente muestra una masa dominante a bajo aumento o puede infiltrar venas, arterias pulmonares y bronquiales, tabiques interlobares y pleura, resultando en un patrón intersticial micronodular (Figura 1). Las áreas adyacentes pueden coalescer por la progresiva invasión del intersticio. Una infiltración perivascular característica está presente en más del $75 \%$ de los casos. Se puede observar un número significativo de células plasmáticas y centros germinales, presentes 
en el $11 \%$ a $70 \%$ de los linfomas pulmonares. Granulomas epitelioideos y células gigantes multinucleadas pueden verse en $20 \%$ de los casos. La mayoría muestra células con mínimas diferencias con los linfocitos normales (un leve aumento de tamaño e hipercromasia nuclear). El citoplasma es usualmente más abundante que el de los linfocitos normales o de los linfomas linfocíticos bien diferenciados. Además, la diferenciación de las células plasmáticas y los nidos de linfocitos plasmacitoides, con o sin cuerpos de Dutcher (inclusiones nucleares PAS+), pueden estar presentes en $65 \%$ de los casos. Las áreas diagnósticas del tumor pueden enmascararse por elementos reactivos como centros germinales, granulomas, plasmocitos y bronquiolitis obliterante, pero la identificación se facilita al concentrarse en áreas entre los centros germinales y alejándose de lugares con cambios secundarios a inflamación.

Otro rasgo característico del tumor es la colonización de los centros germinales. Las células tipo centrocítico pueden infiltrar estas estructuras y obliterarlas. La naturaleza infiltrativa de las células tumorales puede también manifestarse como invasión vascular, que pueden llevar a estenosis del lumen de vasos sanguíneos pulmonares pequeños y medianos en $38 \%$ a $72 \%$ de los casos. También puede verse invasión del cartílago bronquial y extensión intrabronquial.

La lesión linfoepitelial consiste en invasión del epitelio por células tumorales. Los plasmocitos y la diferenciación monocitoide se ven a menudo en la inmediata vecindad de estas estructuras. La infiltración de la pleura por grupos sólidos de células tumorales se ha descrito en $20 \%$ a $85 \%$ de los casos y se considera un carácter diagnóstico de linfoma. Los nódulos linfáticos hiliares pueden ser histológicamente positivos en un $30 \%$ de los casos, pero desafortunadamente se ven rara vez en las biopsias.

Inmunofenotipo. Los linfomas marginales se tiñen inmunohistoquímicamente con una variedad de marcadores para células B como CD20, CD79a e inmunoglobulinas citoplasmáticas (30\%) en cortes congelados y en parafina. Hay usualmente una población de células $\mathrm{T}$ entremezclada. En los cortes con parafina, las células tumorales muestran monoclonalidad por tinción intracitoplasmática de cadenas livianas kappa y/o lambda. La mayoría de los casos muestran cadenas pesadas de $\operatorname{IgM}$. A menudo hay plasmocitos policlonales y células $\mathrm{T}$ reactivas que pueden camuflar áreas diagnósticas y dificultar la interpretación.
Las células del linfoma marginal no expresan CD5 o CD10 o CD23. Esto ayuda a separar este tumor en linfoma linfocítico bien diferenciado, que es CD5 positivo, y el linfoma de células clivadas, que es usualmente CD5 negativo y CD10 positivo. También no muestra evidencia de expresión de los oncogenes bcl-1 y bcl-6. El estudio inmunohistoquímico de los centros germinales muestran predominio de $\operatorname{IgM}$ y un patrón de cadena liviana politípica en la mayoría de los casos. El índice proliferativo con Ki67 es menor de $10 \%$.

Genética molecular. La mayoría de los casos han mostrado reordenación genética de cadena pesada de inmunoglobulinas por técnicas moleculares. Aproximadamente la mitad de los casos presenta $\mathrm{t}(11 ; 18)(\mathrm{q} 21 ; \mathrm{q} 21)$ y ocasionalmente $\mathrm{t}$ $(1 ; 14)$ y trisomía 3.

El ADN del virus de Epstein-Barr no se ha detectado en tumores no asociados a infección por virus de inmunodeficiencia humana, pero se observa comúnmente en linfomas pulmonares asociados a SIDA.

Diagnóstico diferencial. El linfoma marginal o MALT debe diferenciarse de hiperplasia linfoide reactiva. Clásicamente, se han reconocido el pseudolinfoma (PL) y la neumonía intersticial linfocítica (LIP); recientemente se ha agregado la bronquitis/bronquiolitis folicular (BF).

La similitud microscópica con el linfoma BALT con casos comunicados de LIP y PL, el curso clínico indolente, la similar asociación con el síndrome de Sjögren y otras enfermedades autoinmunes, y las publicaciones de linfomas desarrollándose a partir de precursores benignos putativos, han puesto en duda la verdadera existencia de una contraparte reactiva benigna al linfoma de bajo grado pulmonar. Sin embargo, estudios que muestran ausencia de restricción de cadena liviana y reordenación del gen de inmunoglobulina en casos histológicamente reconocidos como BF y LIP apoyan la existencia de estas hiperplasias linforreticulares.

La bronquiolitis folicular BF es considerada la manifestación más temprana de la hiperplasia del BALT. Histológicamente, se caracteriza por nódulos coalescentes de pequeños linfocitos y células plasmáticas con centros germinales alrededor de bronquiolos distales y bronquios con sólo un mínimo componente intersticial. Los grupos de células linfáticas pueden estrechar el lumen de la vía aérea terminal e infiltrar el epitelio. Se puede ver exudado inflamatorio y tapones mucosos y cambios distales como macrófagos espumosos intraalveolares y bronquiolitis obliterante. Estudios inmunohistoquímicos no han 
mostrado clonalidad de cadenas livianas ni se ha identificado reordenación del gen de la cadena pesada de inmunoglobulina. Los linfocitos peribronquiales característicamente reaccionan como células B (CD20+), pero interesantemente, cuando hay casos con un componente intersticial, los linfocitos de los tabiques son células $\mathrm{T}$ $(\mathrm{CD} 3+)$. Este patrón se ve también en LIP, pero no en linfoma de BALT, en el que la mayoría son linfocitos B. Clínicamente, los casos del BF caen en tres amplias categorías: pacientes con inmunodeficiencia congénita o adquirida, especialmente SIDA, pacientes con enfermedad del colágeno, predominantemente artritis reumatoidea con o sin síndrome de Sjögren, y casos idiopáticos, algunos con sospechas de ser reacciones de hipersensibilidad. Cambios histológicos similares a BF se pueden ver también en pacientes con EPOC, bronquiectasias, y fibrosis quística. Radiológicamente, la condición muestra infiltrados bilaterales intersticiales o reticulares. Los síntomas son usualmente leves. Los pacientes se han tratado exitosamente con esteroides y quimioterapia, pero la condición tiende a persistir.

La neumonía intersticial linfocitaria o LIP se ha definido como una hiperplasia difusa del BALT. Desde que se reconoce que la mayoría de las lesiones linfocíticas del pulmón son linfomas de bajo grado, el diagnóstico de LIP es menos frecuente. Los pacientes con LIP y BF caen en categorías clínicamente similares: niños y adultos con SIDA u otros estados de inmunodeficiencia y casos idiopáticos. En este último grupo, el síndrome de Sjögren se encuentra en más del $25 \%$ de los pacientes junto a otras enfermedades autoinmunes. LIP también puede ser inducida por drogas. Los síntomas son similares a los de casos con linfoma. Los pacientes pueden tener disnea y tos, menos frecuentemente fiebre, baja de peso, dolor de pecho y hemoptisis. Las mujeres de mediana edad predominan en los casos con inmunodeficiencia. La radiografía de tórax muestra un infiltrado reticular difuso o infiltrado reticulo-nodular, a veces con densidades localizadas más prominentes en las bases. Hipergamaglobulinemia policlonal se puede ver en 80 a $100 \%$ de los pacientes, pero unos pocos pueden mostrar hipogamaglobulinemia. Evidencia de gamopatía monoclonal hay en casos asilados de LIP, pero este hallazgo sugiere más bien linfoma.

El curso clínico en adultos es difícil de evaluar dado que la mayoría de las series antiguas se realizaron antes de la aplicación de técnicas de diagnóstico modernas. No obstante, de la información disponible, más del 50\% de los pacientes mueren dentro de los 5 años, la mayoría por infecciones asociadas a quimioterapia o esteroides. En niños, la media de sobrevida es 32 meses, significativamente más corta que aquellos con LIP; en pacientes adultos con SIDA, LIP no parece afectar la sobrevida. LIP en pacientes con SIDA muestra ADN de virus de Epstein-Barr en el tejido pulmonar por hibridación in situ, pero la mayoría de los estudios no han mostrado esta asociación en pacientes sin SIDA, excepto casos aislados. Casos de adultos con LIP sin SIDA son raros y difíciles de distinguir de linfoma de bajo grado.

LIP puede definirse histológicamente en un sentido negativo como infiltrado linfoide difuso sin los rasgos de un linfoma de bajo grado. Muestra infiltrado intersticial de linfocitos pequeños con número variable de plasmocitos $\mathrm{y}$ tiene muchos rasgos patológicos de $\mathrm{BF}$, en que se combinan agregados linfoides peribronquiales con infiltración difusa de tabiques alveolares. Son comunes granulomas y centros germinales, particularmente alrededor de las vías aéreas. Característicamente, los tabiques alveolares aparecen infiltrados por células linfoides sin el patrón de engrosamiento marcado y coalescente que se ve en linfoma de bajo grado del BALT. El análisis inmunohistoquímico muestra que los linfocitos de los tabiques alveolares son predominantemente células $\mathrm{T}$, mientras que los linfocitos peribronquiales son linfocitos B; en el linfoma de bajo grado, el infiltrado linfocítico en ambas regiones es predominantemente células B. Esta diferencia en un patrón inmunohistoquímico puede ser de ayuda en distinguir ambas condiciones, pero los métodos más confiables que permiten separar linfoma de bajo grado de LIP son los que demuestran restricción de cadenas livianas. LIP es policlonal mediante todos estos métodos.

\section{Linfoma de células grandes $B$, difuso, alto grado}

Definición. El linfoma de células grandes primario del pulmón es relativamente poco común e histológicamente similar a su homólogo nodal. Se define como una proliferación difusa de células B, neoplásicas, grandes, de tamaño similar o el doble de un macrófago (Figura 3). Se ha denominado también linfoma MALT de alto grado, pero no se recomienda esta terminología. La causa es desconocida, pero se asocia a enfermedad del colágeno, con o sin UIP (neumonía intersticial usual), SIDA y otras inmunodeficiencias.

Cuadro clínico. Es mucho más frecuente la diseminación de un linfoma sistémico al pulmón 
y puede ser histológicamente indistinguible. La mayoría de los pacientes tienen síntomas, con un significativo peor pronóstico que los con un linfoma de bajo grado. Puede haber evidencia histológica de asociación a un linfoma de bajo grado en un número significativo de casos, lo que sugiere transformación. Los estudios de seguimiento muestran una sobrevida de hasta $60 \%$ a 5 años. Se han observado casos con ambos fenotipos B y T.

$\mathrm{a}$

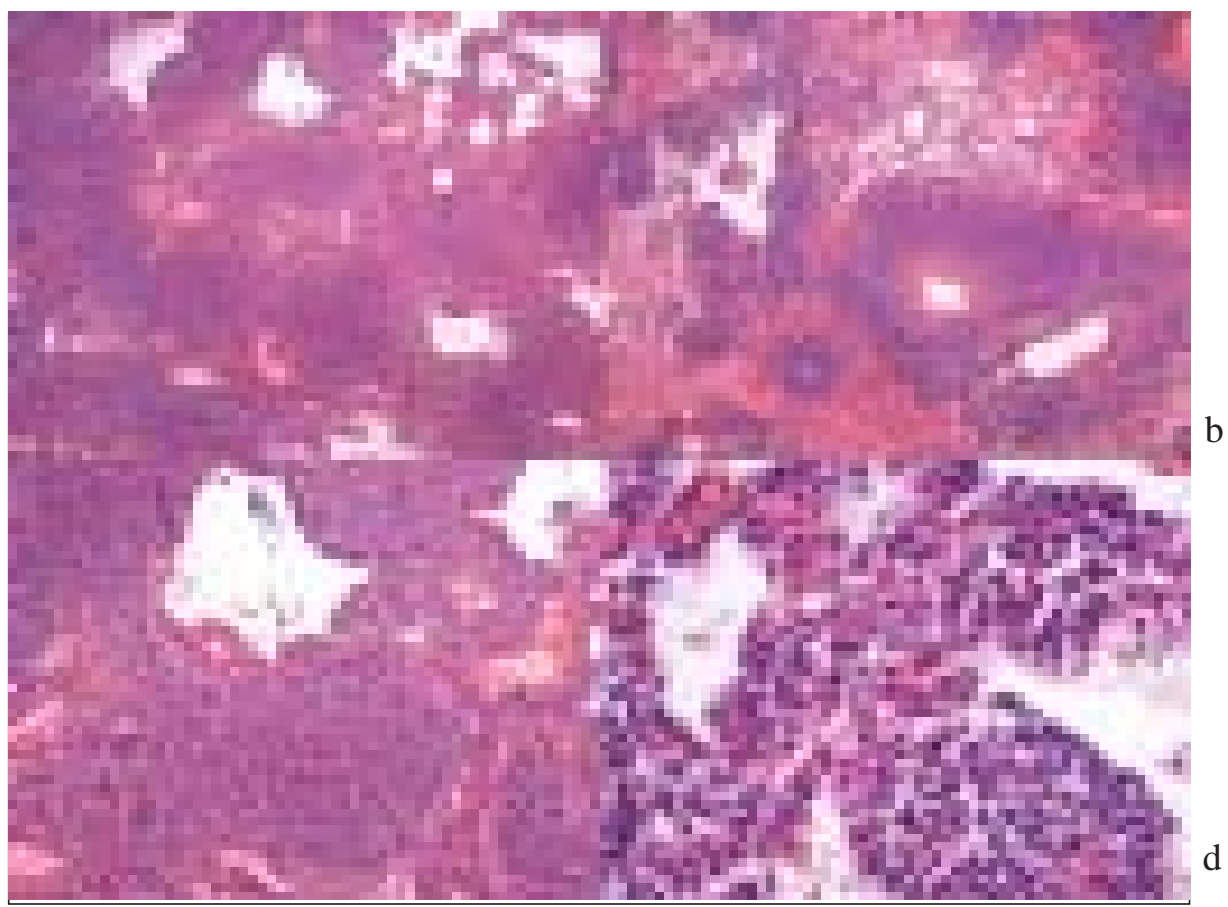

Figura 1. Linfoma MALT de bajo grado. a) infiltración linfoide nodular, perivascular y peribronquial. HE, 20X; b) infiltración linfoide nodular confluente. HE, 20X; c) infiltración linfoide homogénea de células pequeñas. HE, 100X; d) infiltrado tumoral de linfocitos pequeños con diferenciación plasmacitoide. HE 400X.

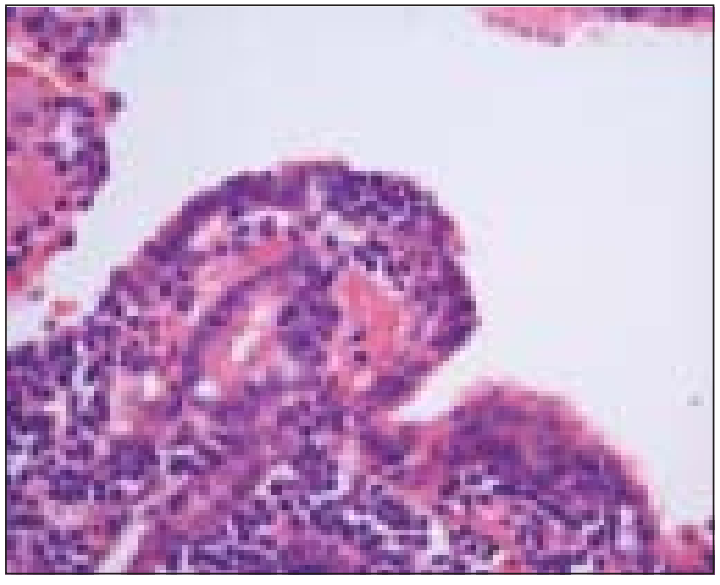

Figura 2. Lesión linfoepitelial caracterizada por infiltración tumoral de linfocitos aislados o en grupos en el epitelio bronquiolar. HE, 400X.

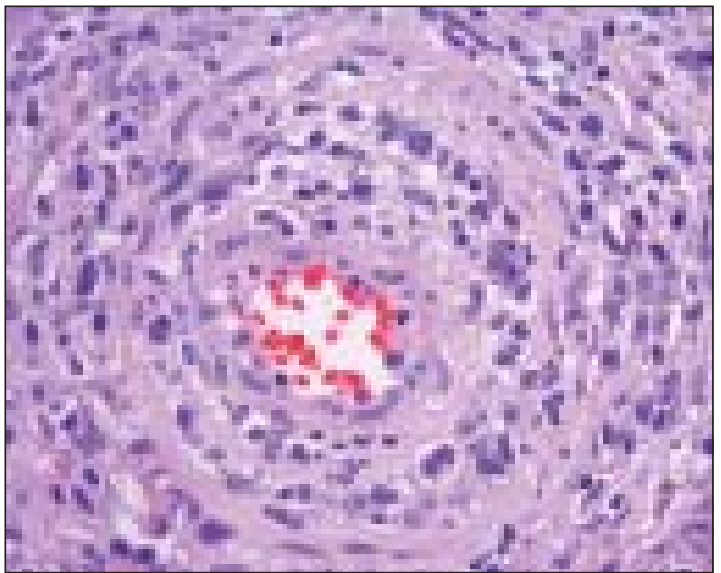

Figura 5. Granulomatosis linfomatoide. Células tumorales linfoides de formas y tamaños variables que invaden pared de vaso sanguíneo en forma concéntrica. HE, 400X. 


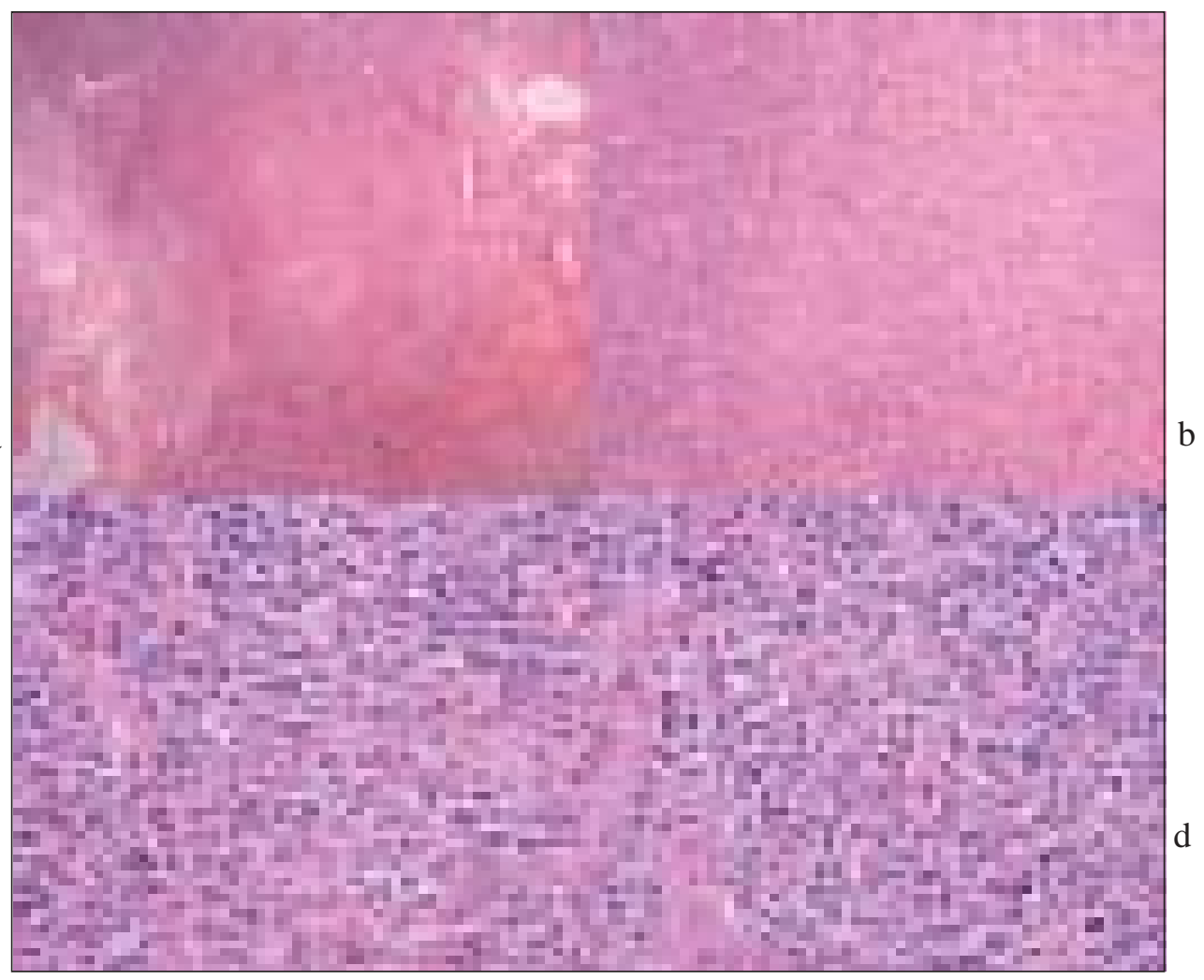

Figura 3. Linfoma B de células grandes, de alto grado. a) infiltración difusa extensa. HE, 20X; b) infiltración conformado nódulos. HE, 20X; c y d) células linfoides grandes citológicamente homogéneas. HE, 400X.

a

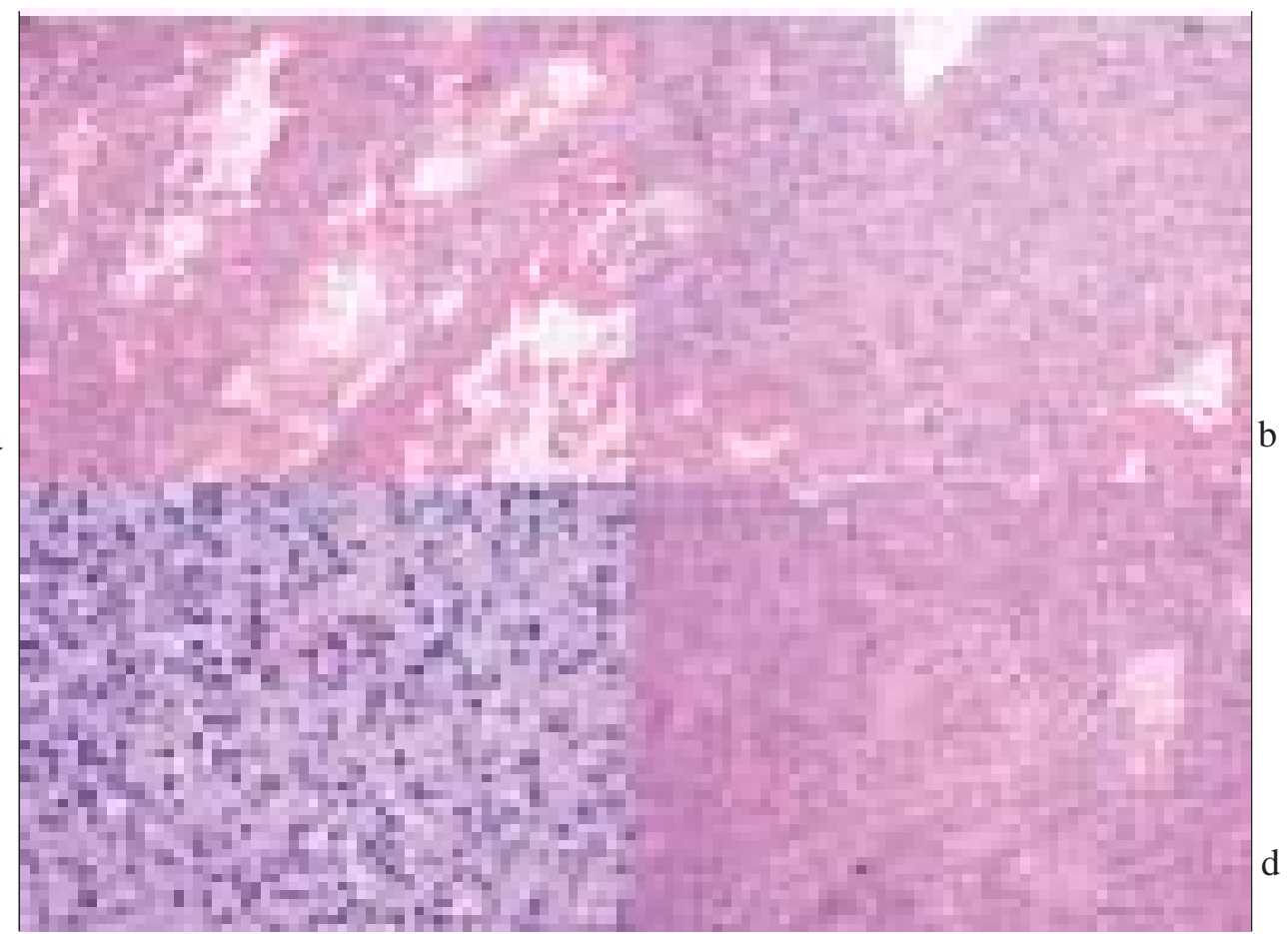

Figura 4. Granulomatosis linfomatoide. a) infiltración linfoide intersticial; b) confluencia de células tumorales conformando nódulos. HE, 20X; c) células grandes de tamaños muy variables. HE 400X; d) tendencia angiocéntrica del infiltrado celular tumoral. HE, 100X. 
Histopatología. Histológicamente, el tumor tiende a estar bien circunscrito, con numerosas mitosis, necrosis e invasión de vasos sanguíneos. El compromiso linfático es generalmente poco visible, pero algunos casos muestran el patrón arquitectural del linfoma de bajo grado e invasión linfática e intersticial.

Inmunofenotipo. Las células tumorales se tiñen con marcadores B como CD20, CD79a e inmunoglobulina citoplasmática.

Genética molecular. Se encuentra reordenación clonal del gen de cadena pesada de inmunoglobulina en aproximadamente el $25 \%$ de los casos.

\section{Granulomatosis Linfomatoide}

Definición. Se define como un trastorno linfoproliferativo semimaligno extranodal angiocéntrico y angiodestructivo de células B atípicas, polimorfas, EBV+, entremezcladas con abundantes células T. Presenta un espectro de agresividad clínica e histológica relacionada con la proporción de linfocitos B grandes EBV+. Se han separados los casos en tres grados histológicos, según la proporción de linfocitos grandes atípicos, lo que se relaciona con la respuesta a la quimioterapia (Tabla 2).

Cuadro clínico. La granulomatosis linfomatoide afecta un amplio espectro de edad, aunque rara vez se ve en niños y adolescentes. El promedio de edad al momento del diagnóstico es en la quinta década de la vida. No existen diferencias entre ambos sexos. Se ha descrito progresión a linfoma B de células grandes.

Histopatología. Esta entidad es histológicamente similar a un linfoma, pero debido al característico infiltrado linfoide pleomórfico, el componente inflamatorio, y la ausencia de linfonodos comprometidos, se escogió no designarla como un linfoma a pesar del mal pronóstico y progresión sistémica en algunos casos. Varios estudios de linfomas pulmonares de células grandes, han identificado casos indistinguibles de una granulomatosis linfomatoide, sugiriendo que los nombres de granulomatosis linfomatoide (GL) y linfoma son intercambiables y que representa un grupo heterogéneo de verdaderos linfomas pulmonares. Histológicamente, se caracteriza por un infiltrado celular polimorfo compuesto por células linfoides grandes atípicas mezcladas con linfocitos pequeños, plasmocitos, histiocitos epitelioideos y otras células inflamatorias (Figura 4). Pueden verse rara vez pequeños granulomas no caseosos. La invasión vascular es el sello de la GL, que muestra un infiltrado transmural de arterias grandes y medias y venas, que puede producir necrosis de la pared del vaso (Figura 5). La oclusión del lumen con extensa necrosis isquémica puede producir zona de infarto con células necróticas tumorales. En GL no se observan necrosis caseosa ni fibrinoide. Todos los casos contienen una proporción variable de células linfoides neoplásicas, grandes, con numerosas mitosis, membrana nuclear irregular, cromatina en grumos y nucléolo prominente.

Inmunofenotipo. Estudios del inmunofenotipo de granulomatosis linfomatoide muestran que la mayoría de las células del infiltrado son linfocitos B y muestran reacción positiva para CD20, CD79a, CD30 y CD43 en algunos casos; CD15 negativo y reacción para EBER-1 y LPM es positiva.

La mayoría de los casos corresponde a lesiones linfoproliferativas B ricas en células T. Las células grandes atípicas se tiñen con marcadores B como CD20 y CD79a y coexpresan LMP (EBV). Los linfocitos pequeños son células $\mathrm{T}$ CD3 positivo.

Genética molecular. Estudios recientes han mostrado que la mayoría de los casos de GL contienen ADN del virus Epstein-Barr. Los estudios moleculares muestran que la población de células B es monoclonal u oligoclonal y que las células $\mathrm{T}$ son policlonales (Jaffe y Wilson, 1997).

\section{Otros Linfomas No-Hodgkin}

Usando la actual clasificación aproximadamente el $90 \%$ de los linfomas pulmonares de bajo grado son linfomas MALT. Los restantes comprenden linfoma folicular, difuso y centrocítico, e inmunocitoma (linfoplasmocitoide).

Varias publicaciones han documentado la ocurrencia de linfoma del manto en mucosas tales como tracto gastrointestinal o amígdalas. Estos tumores se caracterizan por una población neoplásica de linfocitos homogéneamente pequeños, que se asemejan bastante a los del linfoma MALT. Inmunológicamente, los linfocitos son CD5+, CD10- y expresan bcl-1. El linfoma marginal pulmonar es CD5- y CD10-, y no expresa bcl-1. Estos tumores tienden a diseminarse y tienen peor pronóstico. Casos de linfoma del manto aún no han sido reportados en pulmón.

\section{Diagnóstico diferencial}

Debe incluir la hiperplasia linforreticular nodular primaria, antiguamente denominada pseudolinfoma, y otros tumores con alto contenido de linfocitos. 


\section{a. Hiperplasia linforreticular nodular primaria pulmonar}

La hiperplasia linfoide localizada o infiltrado linfoide localizado, -que anteriormente fue denominada pseudolinfoma- se caracteriza por lesiones con centros germinales y plasmocitos, sin compromiso de linfonodos regionales, sin recidivas ni progresión sistémica después de cirugía. Se presenta mayoritariamente en pacientes de edad media y tiene igual incidencia en ambos sexos. La mitad de estos pacientes son asintomáticos, mientras que la otra mitad presenta tos, disnea, dolor torácico, hemoptisis, o síntomas constitucionales como pérdida de peso, fatiga y fiebre. Algunos pacientes pueden tener enfermedades autoinmunes de base, tales como lupus eritematoso, síndrome de Sjögren, o mielitis transversa. El patrón radiológico más común es un nódulo solitario sin calcificación, también puede presentar un patrón infiltrativo solitario, o múltiples nódulos.

El criterio para el diagnóstico histólogico incluye infiltrado linfoide nodular, compuesto por linfocitos maduros y plasmocitos, y un grado moderado de fibrosis. En la mayoría de los casos se pueden ver centros germinales. En un tercio pueden aparecer granulomas epitelioideos. El cartílago bronquial puede mostrar invasión, al igual que la pleura visceral, pero no se ve invasión de la pleura parietal. El pronóstico del pseudolinfoma es excelente. Ningún paciente ha muerto por la enfermedad, pero alrededor de un $30 \%$ presentan recurrencias intrapulmonares y existen casos que han evolucionado a linfoma.

En resumen, el diagnóstico diferencial de hiperplasia linfoide nodular con linfoma MALT de bajo grado es histopatológico, idealmente debe hacerse en una muestra obtenida por toracotomía o videotoracoscopia, y teniendo en cuenta que la hiperplasia nodular es una lesión bien circunscrita, usualmente localizada, con centros germinales reactivos y plasmocitos y linfocitos pequeños interfoliculares, sin colonización de los folículos por células neoplásicas, ausencia de cuerpos de Dutcher y lesiones linfoepiteliales; el análisis inmunohistoquímico de cadenas livianas kappa y lambda muestra reacción policlonal con reacción negativa para bcl-2 en centros germinales. En cambio, en el linfoma, la lesión suele ser difusa con invasión de pleura y cartílago, con infiltrados celulares polimorfos de células B monocitoides, linfocitos atípicos, plasmocitos, con colonización de centros germinales, cuerpos de Dutcher y lesiones linfoepiteliales; aproximadamente el $40 \%$ de los casos muestra restricción de cadenas livianas (monoclonal) y bcl-
2 es positivo en los linfocitos que colonizan centros germinales.

\section{b. Otros tumores}

El carcinoma del pulmón tipo linfoepitelioma o carcinoma linfoepitelial es una rara variedad de carcinoma debe incluirse en el diagnóstico diferencial de linfoma pulmonar. Histológicamente, el tumor es idéntico a los carcinomas linfoepiteliales que más comúnmente se ve en nasofaringe. Se observan nidos cohesionados de células epiteliales grandes, que conforman nidos con patrón sincicial, abundantes plasmocitos y linfocitos en el estroma, que pueden extenderse e infiltrar los nidos epiteliales. Arquitecturalmente, algunos tumores presentan fascículos de células fusiformes, mientras que otros son predominantemente células epitelioideas. El núcleo es usualmente redondo u ovalado. Este aspecto histológico se puede confundir fácilmente con linfoma debido a la densidad del infiltrado linfoide y a la dificultad de discernir el componente epitelial. El estudio inmunohistoquímico puede ser de ayuda cuando se utilizan anticuerpos para citoqueratinas, que permiten visualizar bien los nidos epiteliales.

La incidencia es semejante en ambos sexos, el rango de edad va de 40 a 80 años con un promedio de 56 años.

\section{Histiocitosis de células de Langerhans}

Esta condición también se denomina granuloma eosinófilo del pulmón, histiocitosis X del pulmón y granulomatosis de células de Langerhans del pulmón. En 1996 publicamos una descripción detallada de la enfermedad, su diagnóstico diferencial clínico y patológico, como también una discusión de su patogenia, por lo que invitamos a consultarla ${ }^{1}$.

\section{Bibliografía}

1.- GONZÁLEZ S. Histiocitosis de células de Langerhans del pulmón. Rev Chil Enf Respir 1996; 12: 20-4.

2.- ABBONDANZO S L, RUSH W, BIJWAARD K E, KOSS M N. Nodular lymphoid hyperplasia of the lung. A clinicopathological study of 14 cases. Am J Surg Pathol 2000; 24: 587-7.

3.- AHMED S, KUSSIC S J, SIDDIQUI A K, BHUIYA T A, KAHN A, SAREWITZ S, et al. Bronchial-associated lymphoid tissue lymphoma. A clinical study of a rare disease. Eu J Cancer 2004; 40: 1320-6.

4.- TRAVIS W D, BRAMBILLA E, MÜLLER-HERMELINK H K, HARRIS C C (eds). Pathology and Genetics of Tumours of the Lung, Pleura, Thymus and Heart. WHO Classification of Tumours. IARC Press, Lyon 2004.

5.- TRAVIS W D, COLBY T V, KOSS M N, ROSADODE-CHRISTENSON M L, MÜLLER N L, KING JR T E 
(eds). Non-neoplastic disorders of the lower respiratory tract. Atlas of nontumor Pathology, American Registry of Pathology, AFIP, Washington 2002.

6.- HARRIS N L, JAFFE E S, STEIN H, BANKS P M, CHAN J K, CLEARY M L, et al. A revised EuropeanAmerican classification of lymphoid neoplasms: a proposal from the International Lymphoma Study
Group. Blood 1994; 84: 1361-92.

7.- CRADANEL J, WISLEZ M, ANTOINE M. Primary pulmonary lymphoma. Eur Resp J 2002; 20: 75062.

8.- KIM J H, LEE S H, PARK J O, KIM K, KIM W S, JUNG C W, et al. Primary pulmonary non-Hodgkin lymphoma. Jpn J Clin Oncol 2004; 34: 510-4. 